\title{
Blog Quality Assessment Tool (BQAT)
}

\author{
Zuhaira Muhammad Zain \\ Faculty of Computer and Information Sciences \\ Princess Nourah Bint Abdulrahman University \\ Riyadh, KSA
}

\author{
Abdul Azim Abd Ghani \\ Faculty of Computer Science and Information \\ Technology \\ Universiti Putra Malaysia \\ Serdang, Malaysia
}

\begin{abstract}
A blog quality model and guidelines to determine important features of different blog categories have been proposed to determine blog quality and to promote readers' satisfaction. However, no tools have been developed to assist blog readers in the evaluation of their favorite blogs based on their blog satisfaction. This paper discusses each process in the development of the Blog Quality Assessment Tool (BQAT) in detail. The main functions of the BQAT are to calculate the probability of a blog to be of good quality based on blog-reader satisfaction, and to accumulate the results for the assessed blog. Thus, blog-readers can easily assess their favourite blogs and obtain information on the quality of the blogs visited. This study also shows that the more satisfied the blog is, the higher its quality.
\end{abstract}

Keywords: Blog Quality, Blog Quality Model, Rasch Analysis, Blog Quality Assessment Tool

\section{INTRODUCTION}

Scholars have shown increasing interest in blog success by providing blog design advice and checklists [1, 2, 3, 4]. Nevertheless, these criteria are merely based on individual authors' or bloggers' opinions. 49 blog quality criteria have been consolidated by Zain et al. [5, 6, 7] drawn from related studies focused on website design criteria [8], web information quality criteria for different domains including ecommerce [9], data integration [10], decision making [11], organizational networks [12], personal websites [13, 14], web portals [15], criteria extracted from design advice and checklists [16, 3, 17], and design articles extracted from popular blogs [18, 1, 2, 4, 19]. Zain and Ghani [20] provided a relative importance analysis that can help bloggers/blog evaluators/readers focus on the most important criteria during blog category examination. Yet, no tools have been developed to assist blog readers in the evaluation of their favorite blogs based on their blog satisfaction. This study describes the development of a blog quality assessment tool to assist blog readers in the evaluation of their favorite blogs based on their blog satisfaction. This will help maintain blog quality in the blogosphere.

\section{RELATED WORKS}

Quality is an essential factor in the information technology environment. It is an important requirement in information technology-related development (i.e. software, website, and information system domains). It is a composite of many characteristics that operate in particular development domains. Quality might be conceptualized as a quality model/framework that depicts composite characteristics and their relationships. Each model/framework can guide developers/designers during quality product production (e.g. software, data, websites, or information). Alternatively, users can employ a model/framework to evaluate those products. Some commonly accepted software quality models include McCall et al.'s [21], Boehm's [22], Dromey's [23], and the ISO/IEC 9126 quality model [24]. They often serve as foundations for other models in different domains such as website and data development.
Quality is vital to the website development community. Website quality models comprise the Web Quality Evaluation Method (WEBQEM) [25], Web Quality Model (WQM) [26], and a model designed for web-based applications [27]. These models can be applied to evaluate the overall quality of webbased applications. Nevertheless, most concentrate on the usability aspects and lack aesthetic and reputational features. Malak [27] proposed another model to assess quality that highlights on criteria that influence webpage navigational design quality (e.g. information links) and availability of navigational features (e.g. menus and search tools). Even though it attempts to incorporate design features to assess quality, it does not include many important design features, such as multimedia and visual design. A systematically study on important design features of different website domains based on user satisfaction and expectations has been done by Zhang et al. [8]. They described 77 website features and grouped them into 15 feature families. They incorporated aesthetic aspects (e.g. multimedia, visual design, and attractive layout, as well as reputational aspects (e.g. site or company reputation and rewarding experience). These models can be used by Website developers/designers as guidelines during high-quality website development. Furthermore, website users/ evaluators can rely on them to evaluate website quality. For instance, WebQEM has been used to assess websites in different domains including museums [28], academia [29], and e-commerce [30]. Blog characteristics are similar to website characteristics. Therefore, many website quality features are used to determine blog quality. Yet, some features are not relevant to blog quality measurement (e.g. Product and Service Concerns and Security). Hence, we focused on personal blogs because most security criteria solely benefit blog owners, rather than blog readers.

Quality is very essential to the information quality community. Quality begins within the context of management information systems [31, 32] and extends to other contexts, such as cooperative systems [33], data warehouses [34, 35], and electronic commerce [36,9]. Scholars now focuses on web information quality [37] because of increased awareness of differences between Web applications and traditional information systems. Caro et al. [15] argued that a gap exists among types of information quality specifically developed for web portals. They discovered 33 significant criteria for portal 
data quality based on users' perspectives. However, their model failed to include criteria (e.g. search tools and chat rooms). They solely addressed data quality, rather than the entire Web portal. In addition, some criteria are irrelevant and inappropriate for blog quality determination.

Quality is very essential to the blogging community. Blog design advice and checklists include criteria that might influence users' satisfaction (e.g. readability, navigability, clarity, and commentary) [3]. Nevertheless, individual authors defined most criteria. Banks [16] interviewed 30 of the world's top bloggers. He summarized the results and offered suggestions for successful blogging. Yet, the suggested criteria, (e.g. originality, relevant information, and easy navigation), are useful only from bloggers' perspectives. Hopkins [18] conducted a systematic preliminary study focused on ideal blog types. He identified that ideal blogs include comments, photos, and primarily original materials. Ideal blogs feel personal. However, based on our literature review, no empirical evidence confirmed that these criteria are ample and complete. Blog quality includes all blog characteristics that determine a blog's ability to satisfy stated and implied needs [7]. Zain et al. [5, 6, 7] constructed a blog quality model by determining a set of criteria based on a review of relevant studies and blogs. They measured these criteria's acceptability based on questionnaire surveys completed by a sample population of blog readers [7]. The blog quality model comprised of 11 families decomposed into 49 quality criteria that can be used by the blog evaluators to determine blog quality. Bloggers can use it to promote readers' satisfaction. Zain and Ghani [20] provided guidelines that blog designers/evaluators can employ to determine important features of different blog categories. However, no tools have been developed to assist blog readers in the evaluation of their favorite blogs based on their blog satisfaction.

\section{METHODOLOGY}

A prototype of the Blog Quality Assessment Tool (BQAT) was developed in accordance with the processes proposed by Sommerville [38] as follows:

\subsection{Initial analysis}

In this process, basic requirements including the blog quality criteria, desired input and output information were determined. Before specifying the blog quality criteria, we determine the assessors and the assessment process. By reviewing studies on website quality, we determine that quality can be assessed in three different ways: users' view, developers' view, and managers' view [39, 40, 41].

Users are interested in performance quality, primarily an external characteristic, while developers and managers are more concerned with internal quality issues such as maintainability, portability, cost effectiveness, and so on. However, in our case, as our focus is primarily on personal blogs, we can assess these from both blog-readers' and bloggers' viewpoints. Blogs, like websites, focus on users' perspective, an external aspect of quality.

External quality can be defined through both functional and non-functional properties. Apart from functional properties, non-functional properties such as easy to understand, correctness and originality, contribute significantly to blog quality.

In line with suggestions proposed by Evans and King [42] to evaluate Web-based applications, a blog assessment must be comprehensive, constituting five major components: (i) blog categories (the broad areas to be investigated), (ii) quality factors (specific elements pertaining to each blog category), (iii) weights (relative importance of each blog category and quality factor), (iv) ratings (scores assigned to each category and quality factor), and (v) total score (an overall score based on the weights and ratings).

The first step was to identify the quality factors for a blog. These were determined by Zain et al. [7]. Subsequently, the quality factors were assigned weights; the greater the weight, the more important the quality factor. The weight for each blog category and quality factor was obtained from Zain and Ghani [20]. Subsequently, blog-readers review a blog and rate the quality factors based on their level of satisfaction with the respective factor. The ratings were treated as input in the BQAT prototype. A quality factor total score was then obtained by multiplying the assigned weights with the respective ratings. Finally, the quality factor scores were aggregated to obtain an overall quality score, the BQAT output, for the respective blogs. As the Rasch Measurement Model was used to determine the output, it was referred to as 'the probability of the blog to be a good quality blog'.

\subsection{Define the prototype objective}

The objective of developing the prototype was twofold: (i) to apply the proposed blog quality model, and (ii) to assist readers or bloggers to assess blog quality.

\subsection{Specify the prototype}

All functions relevant to the blog quality assessment were listed, and then each function was either accepted or rejected for inclusion in the prototype system as shown in Table 1 and Table 2.

Table 1. Functions included in the prototype

\begin{tabular}{|c|c|}
\hline Functions & Remarks \\
\hline Blog rating & Rating satisfaction using radio buttons. \\
\hline $\begin{array}{c}\text { Error } \\
\text { handling } 1\end{array}$ & $\begin{array}{l}\text { If user misses to rate a criteria, a prompt, } \\
\text { "Please complete your assessment on the } \\
\text { criteria!" will be displayed. }\end{array}$ \\
\hline $\begin{array}{l}\text { Blog quality } \\
\text { estimation }\end{array}$ & $\begin{array}{c}\begin{array}{c}\text { Calculates the probability of the blog being of } \\
\text { good quality }\end{array}\end{array}$ \\
\hline $\begin{array}{c}\text { Error } \\
\text { handling } 2\end{array}$ & $\begin{array}{l}\text { If there are less than } 30 \text { respondents a prompt, } \\
\text { "Insufficient Statistics! Data is not enough to } \\
\text { construct a reliable result!", will be displayed. }\end{array}$ \\
\hline Navigation & $\begin{array}{l}\text { User can click on the BQAT banner, Start, } \\
\text { Next, and Submit buttons. }\end{array}$ \\
\hline
\end{tabular}

Table 2. Functions excluded from the prototype

\begin{tabular}{|c|c|}
\hline Functions & Remarks \\
\hline $\begin{array}{c}\text { Registration } \\
\text { of blogger }\end{array}$ & $\begin{array}{c}\text { A page where bloggers wishing to participate } \\
\text { in the blog assessment project can register } \\
\text { their blogs. }\end{array}$ \\
\hline $\begin{array}{c}\text { Submit data } \\
\text { to database }\end{array}$ & Send blogger's data to the BQAT database. \\
\hline $\begin{array}{c}\text { Send banner } \\
\text { and URL }\end{array}$ & $\begin{array}{c}\text { Automatically email the banner and URL of } \\
\text { the blogger's assessment page to the blogger. }\end{array}$ \\
\hline
\end{tabular}

All functions in Table 2 were excluded from the prototype as this study only focuses on the methods to rate a blog and to assess its quality. In order to include these functions, a dummy blog (see Figure 3), with a BQAT banner linking to the blog assessment page, was created. Moreover, the dummy 
blog was used to demonstrate how blog readers can attempt the blog assessment and how the BQAT accumulates the results. The details of the dummy blog were manually input in the BQAT database owing to time and cost constraints.

\subsection{Prototype construction}

The BQAT was built using WAMPSERVER technology. It consists of three principal components; Apache web server, MySQL database and PHP scripting language. This package is free and very easy to use enabling easily manipulation of information held in a database and dynamic generation of web pages each time a browser requests for content. PhpMyAdmin program is also included in this package, providing a graphical user interface for the MySQL database manager. The architecture of the BQAT system is depicted in Figure 1.

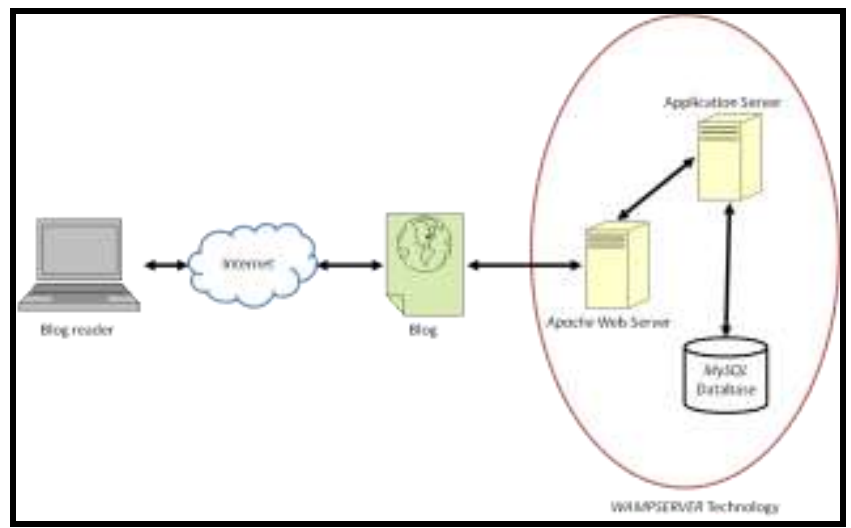

Figure 1. BQAT architecture

The BQAT prototype was developed as per the flow-chart shown in Figure 2.

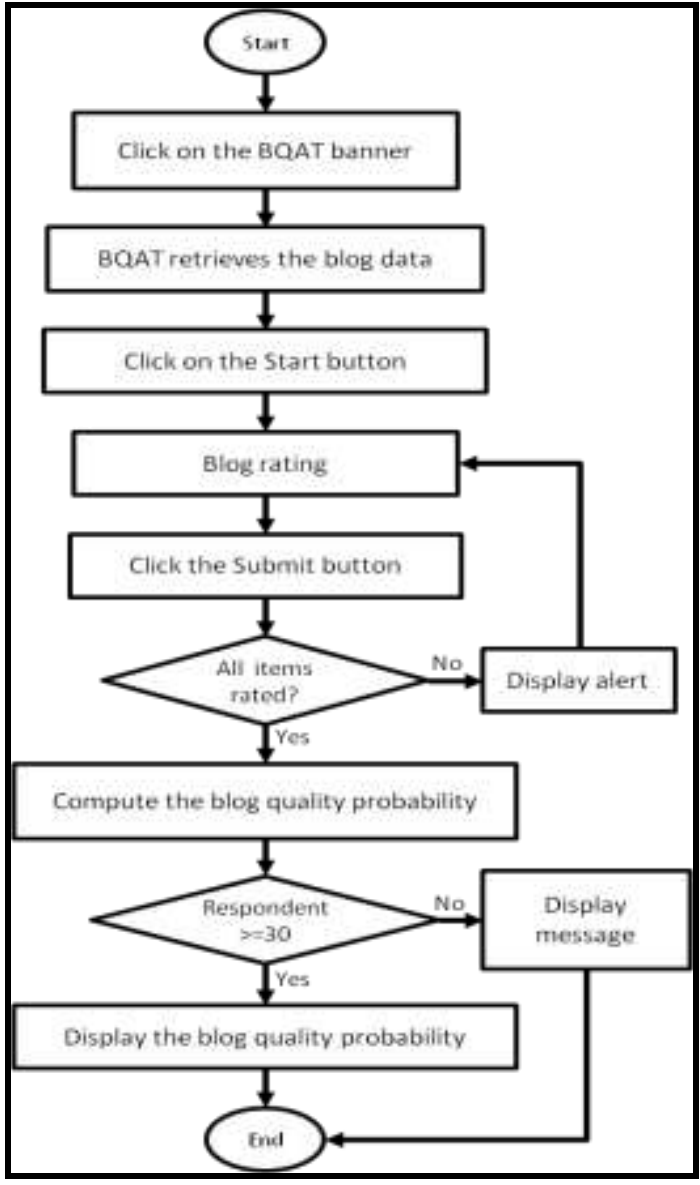

Figure 2. Flow chart

The process starts with the blog-reader clicking on the BQAT banner in a dummy blog (see Figure 3). This will submit the blog ID parameter to the BQAT system. 


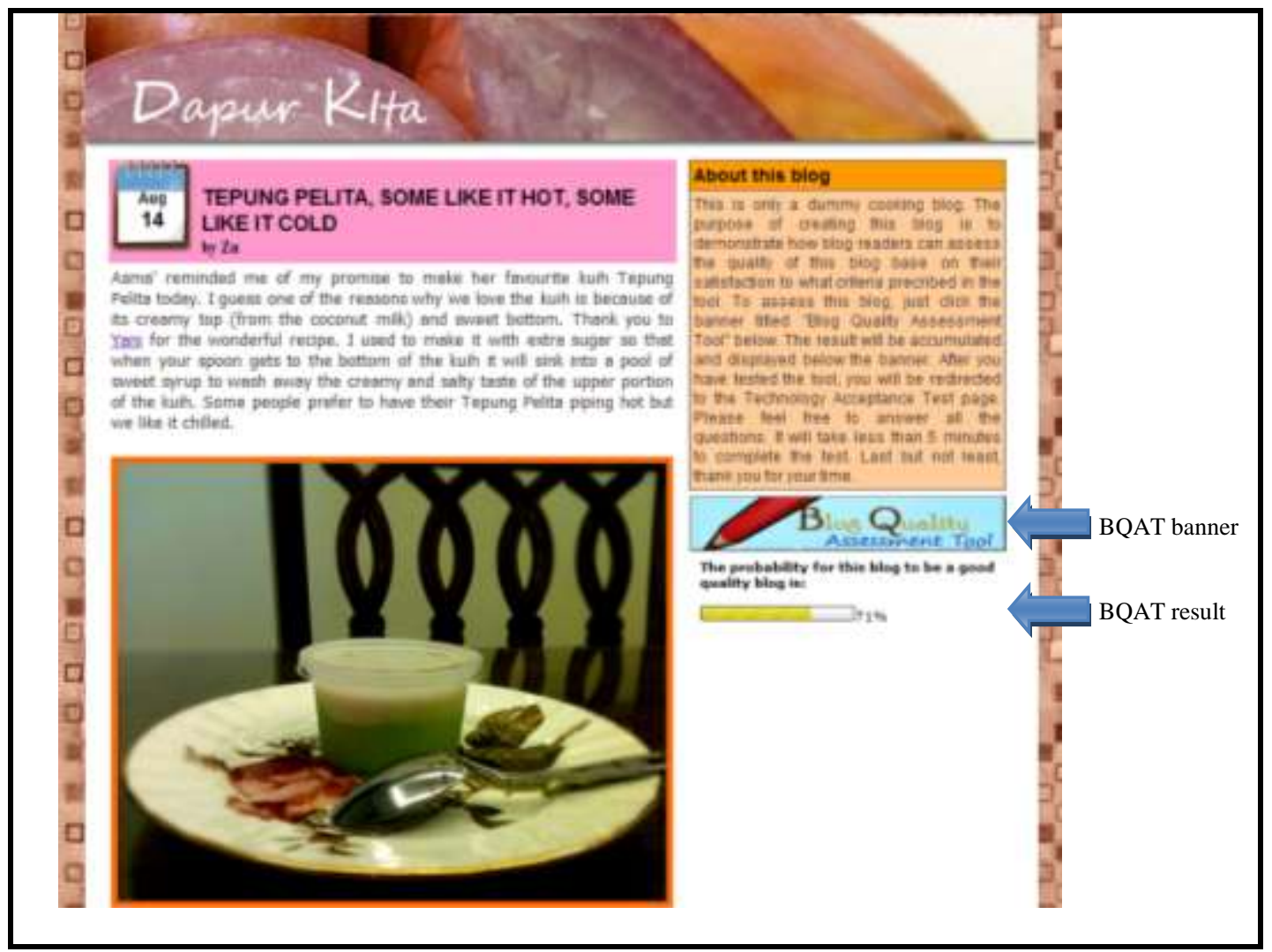

Figure 3. Dummy blog

Using the blog ID, BQAT retrieves the following blog data: blog name, URL, and blog type from the BQAT database. BQAT then displays the data on the introductory page (see Figure 4). Next, the blog-reader clicks the Start button on this page to commence the blog assessment.

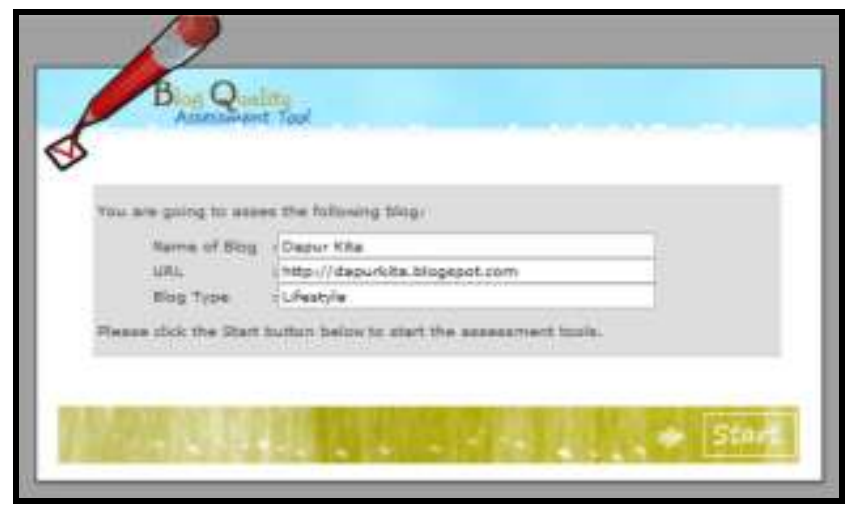

Figure 4. Introductory Page of the Blog Quality Assessment Tool

The blog rating consists of eleven pages (see Figure 5 - 15), each representing one of the 11 families of blog quality criteria, respectively. Blog-readers rate the blog by stating their level of satisfaction for the respective criteria in each family on a 5-point Likert scale (1: Not satisfied to 5: Very satisfied) represented by radio buttons. Each page is linked to its following page by a Next button. When a Next button is clicked, all fields in the respective page are verified to confirm whether they have been filled.

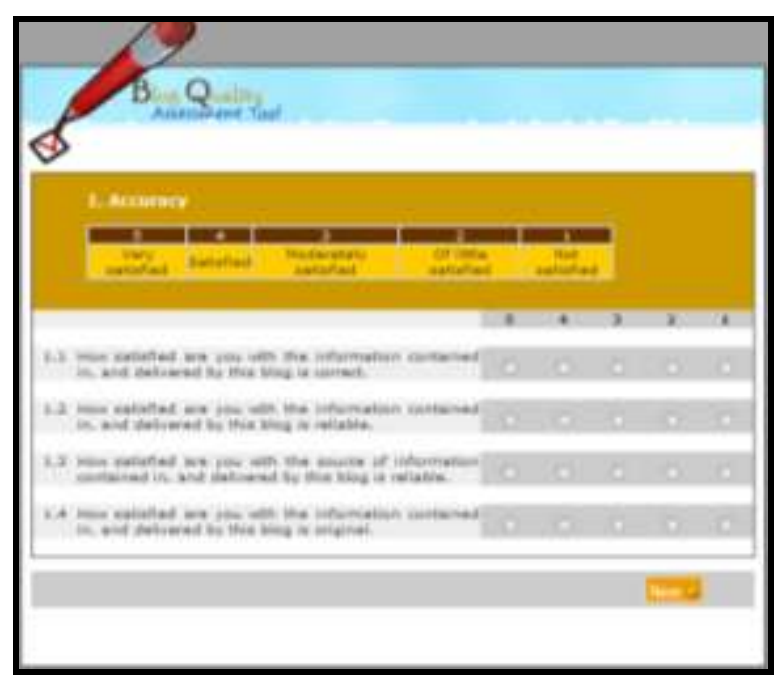

Figure 5. Accuracy Page 
International Journal of Computer Applications Technology and Research

Volume 4- Issue 11, 846 - 859, 2015, ISSN:- 2319-8656

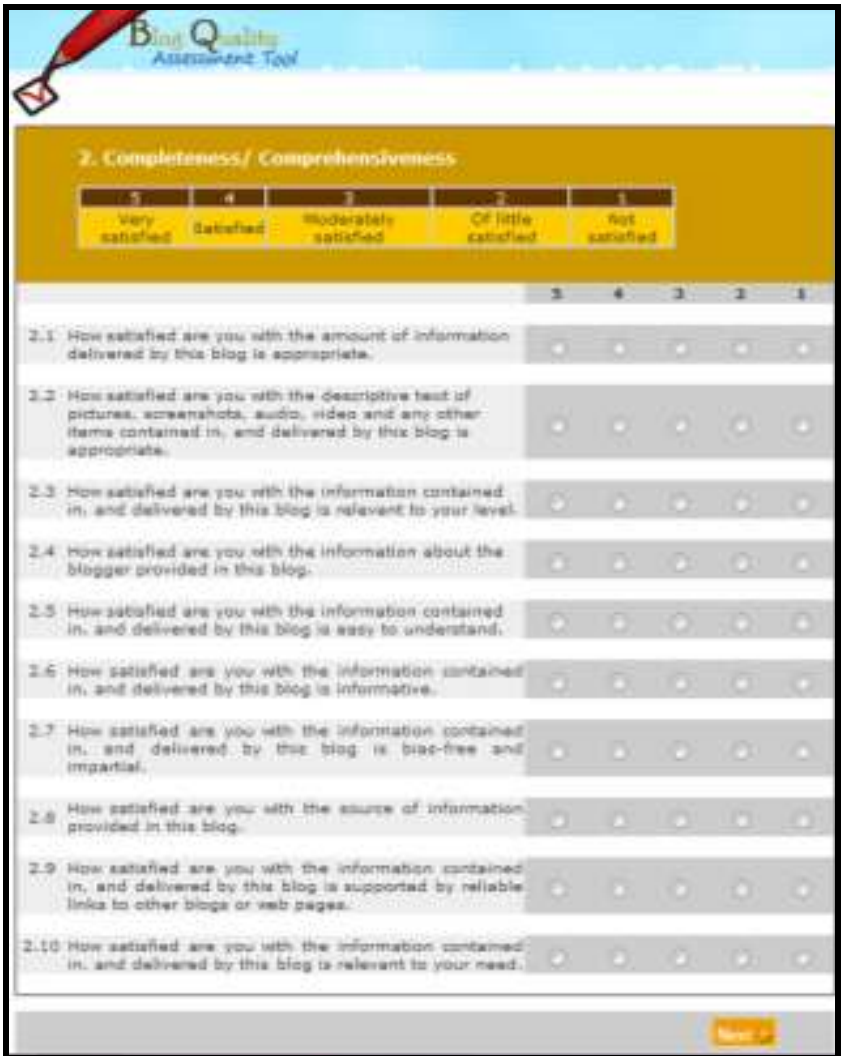

Figure 6. Completeness/Comprehensiveness Page

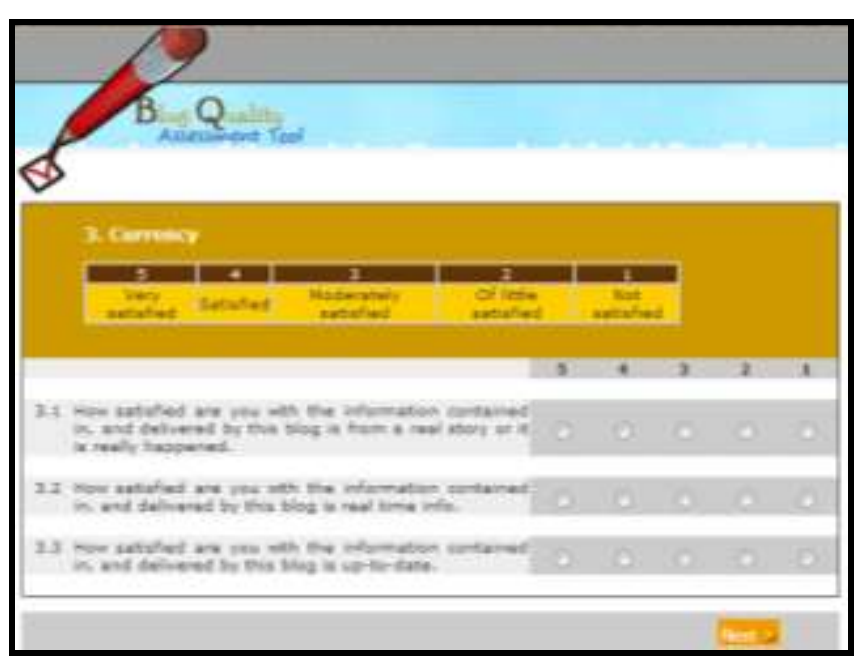

Figure 7. Currency Page

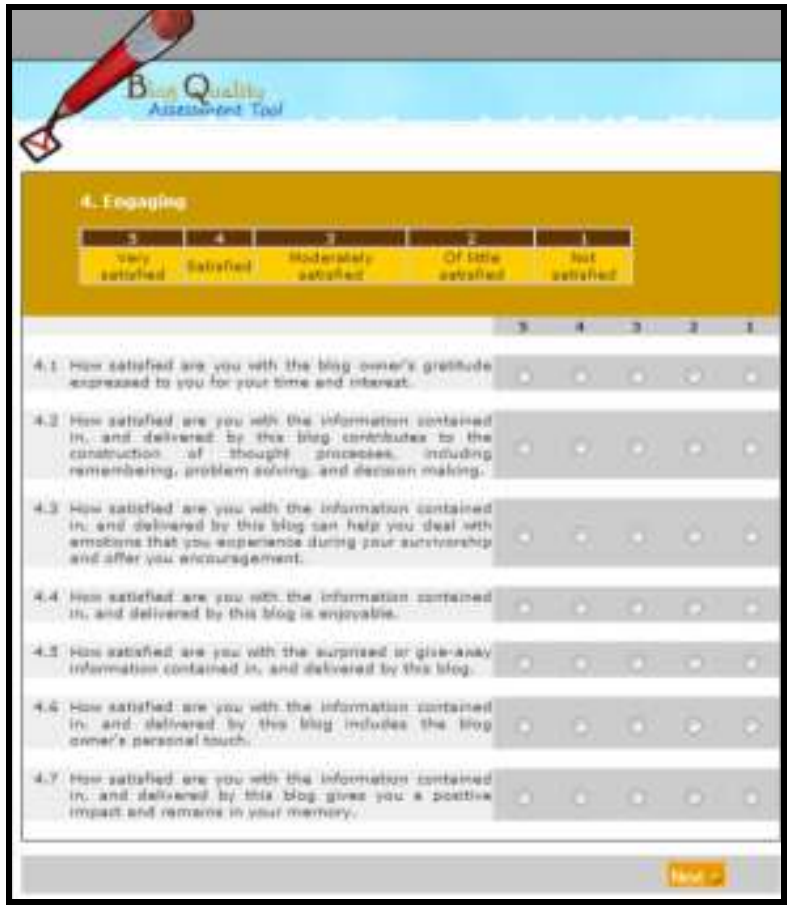

Figure 8. Engaging Page

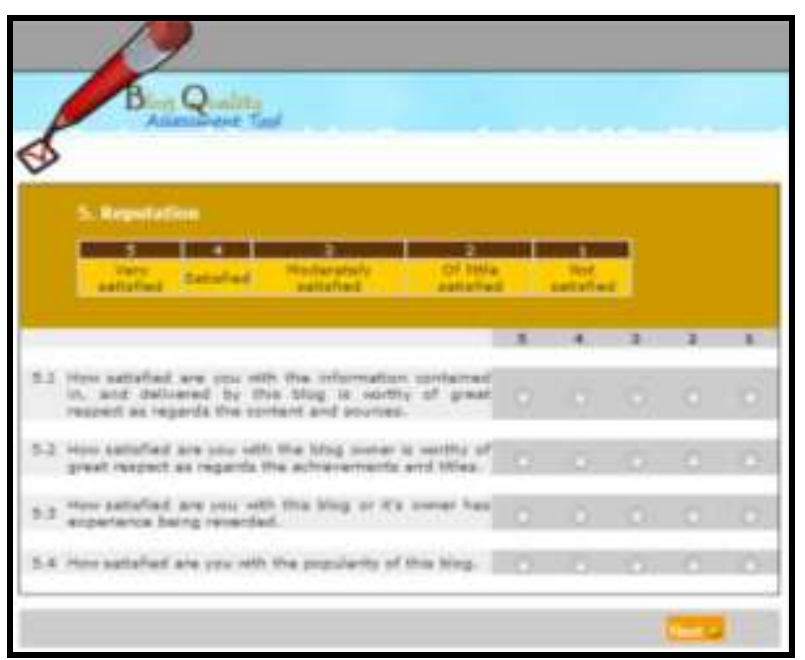

Figure 9. Reputation Page

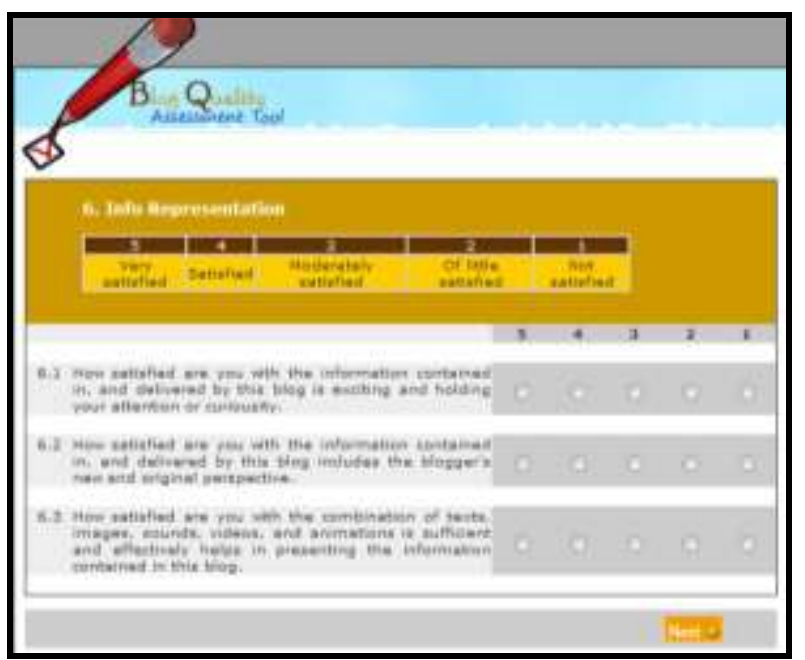

Figure 10. Info Representation Page 


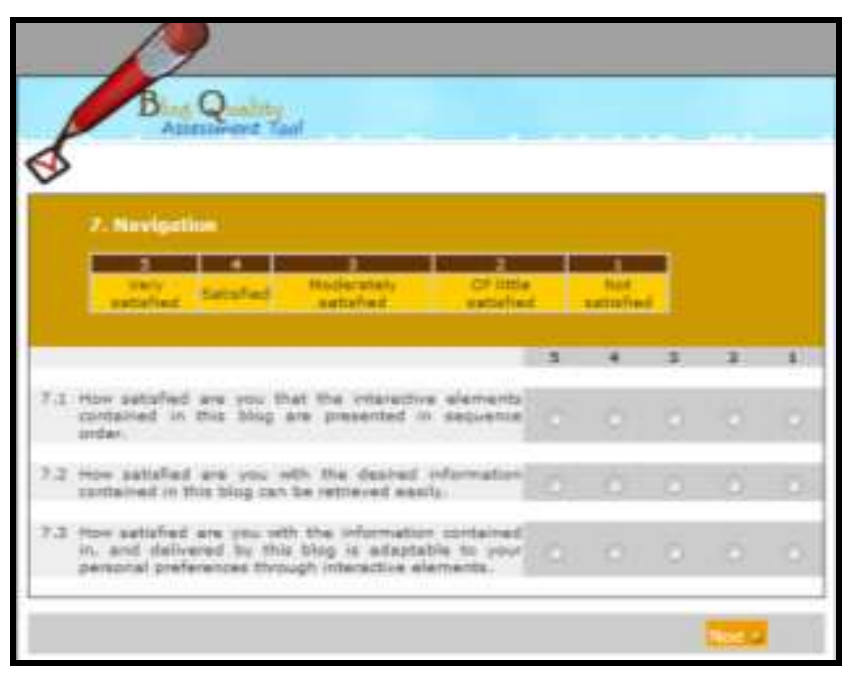

Figure 11. Navigation Page

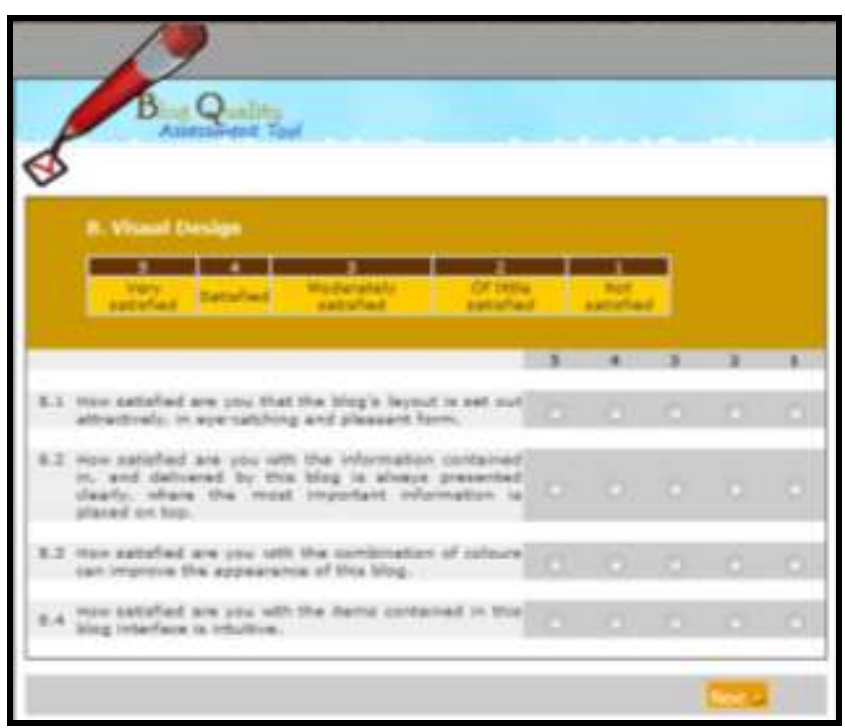

Figure 12. Visual Design Page

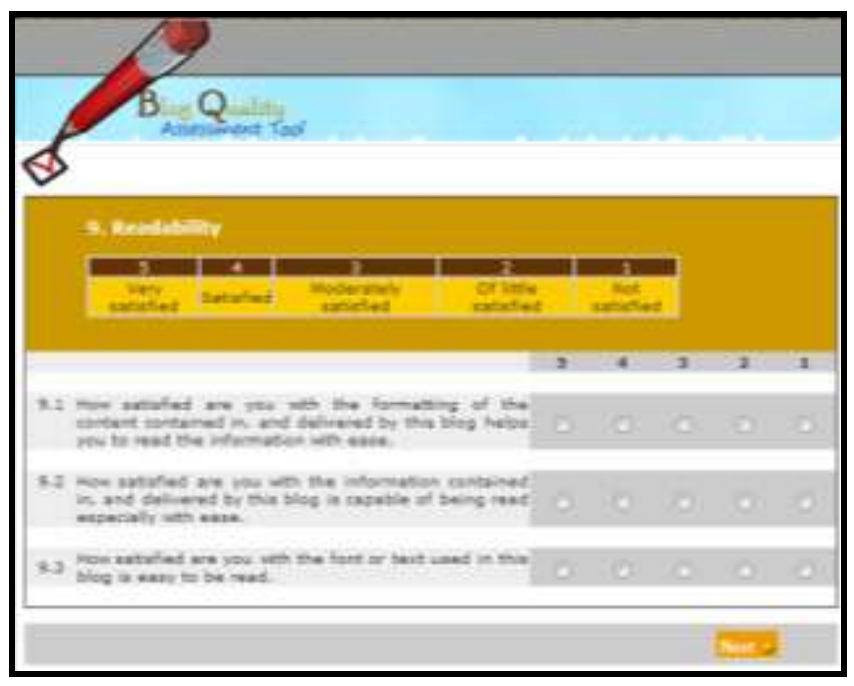

Figure 13. Readability Page

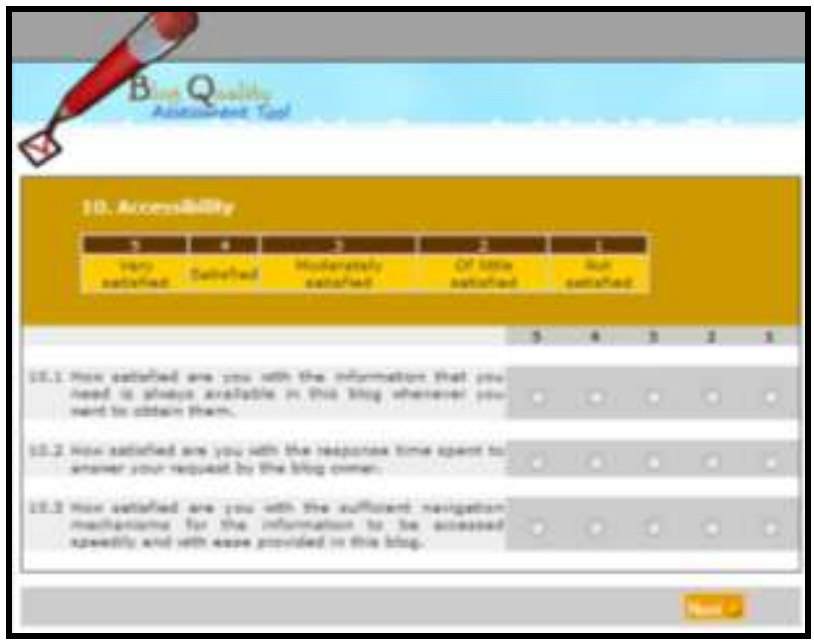

Figure 14. Accessibility Page

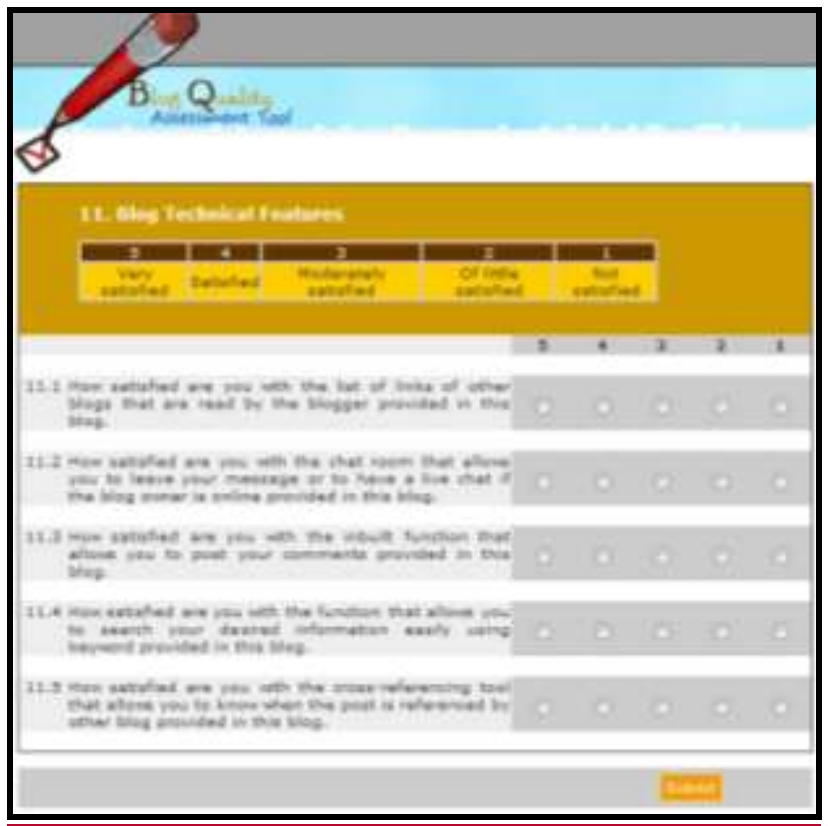

Figure 15. Blog Technical Features Page

If the blog-reader does not rate a particular criterion, an error message will pop-up (see Figure 16). After completing the blog rating, the blog-reader clicks on the Submit button in the Blog Technical Features page (see Figure 15).

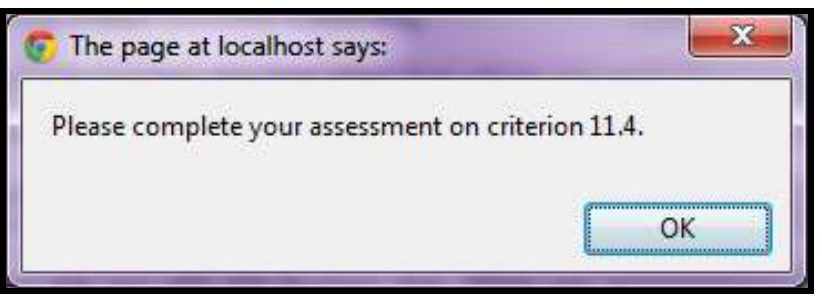

Figure 16. Error message

The rating of the criteria uses Likert's scale to produce ordinal data. Hence, upon submission, the Rasch Model was applied to convert the ordinal data into interval data and then used to estimate the probability of the blog to be of good quality. The system verifies whether the number of respondents is adequate to provide a meaningful result. If the number of 
respondents is equal to or greater than 30 , then the result will be displayed as follows (see Figure 17).

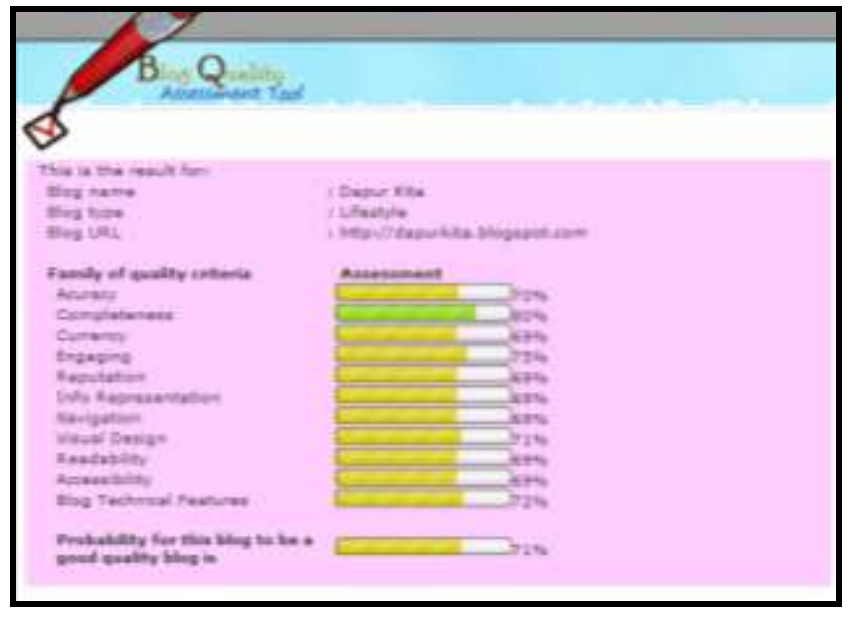

Figure 17. Result Page

On the contrary, in case of less than 30 respondents, the result is displayed as shown in Figure 18.

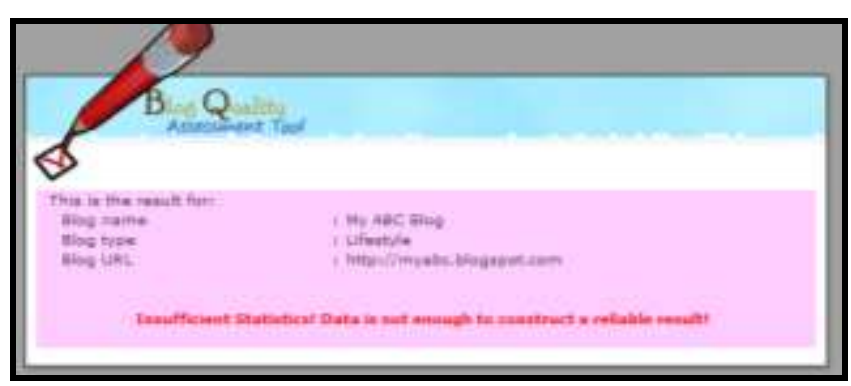

Figure 18. Insufficient Statistics

There were six steps involved in estimating the probability of a blog to be of good quality based on the Rasch Rating Scale Model [43]. These were as follows:

\section{Step 1: Estimate the level of satisfaction for item $i$}

The raw scores were converted into odds of success by calculating the ratio of the number of people who answered the item on any scale $(x)$ to the number of people who did not answer on that scale $(n-x)$. For example, if the total number of respondents $(n)$ is 30 , a raw score $(x)$ of 7 on the Very Satisfied (5) scale for item 1 (see Table 3) is divided by the number of people who did not answer Very Satisfied for item $1(n-x)$, that is, 23 , to obtain the ratio $7 / 23$ (see Table 4). The natural $\operatorname{logs}$ of these odds (e.g., $\log _{10} 7 / 23=-0.52$ ) are shown in Table 5.

Table 3. Example of Raw Scores

\begin{tabular}{|c|c|c|c|c|c|}
\hline Dimension 1 & $\mathbf{5}$ & $\mathbf{4}$ & $\mathbf{3}$ & $\mathbf{2}$ & $\mathbf{1}$ \\
\hline Item 1 & 7 & 13 & 5 & 3 & 2 \\
\hline Item 2 & 2 & 18 & 5 & 3 & 2 \\
\hline Item 3 & 3 & 12 & 10 & 3 & 2 \\
\hline Item 4 & 3 & 11 & 11 & 3 & 2 \\
\hline
\end{tabular}

Note: 5 - Very Satisfied, 4 - Satisfied, 3 - Moderately Satisfied, 2 - Of Little Satisfied, 1 - Not Satisfied
Table 4. Example of Ratio $(x / n-x)$ for Each Item on Each Scale

\begin{tabular}{|c|c|c|c|c|c|}
\hline Dimension 1 & $\mathbf{5}$ & $\mathbf{4}$ & $\mathbf{3}$ & $\mathbf{2}$ & $\mathbf{1}$ \\
\hline Item 1 & $7 / 23$ & $13 / 17$ & $5 / 25$ & $3 / 27$ & $2 / 28$ \\
\hline Item 2 & $2 / 28$ & $18 / 12$ & $5 / 25$ & $3 / 27$ & $2 / 28$ \\
\hline Item 3 & $3 / 27$ & $12 / 18$ & $10 / 20$ & $3 / 27$ & $2 / 28$ \\
\hline Item 4 & $3 / 27$ & $11 / 19$ & $11 / 19$ & $3 / 27$ & $2 / 28$ \\
\hline
\end{tabular}

Note: 5 - Very Satisfied, 4 - Satisfied, 3 - Moderately Satisfied, 2 - Of Little Satisfied, 1 - Not Satisfied

\section{Step 2: Calculate Item Mean for Dimension 1}

The Item Mean for Dimension 1 was calculated by aggregating the total of the natural logs of the odds for all items, divided by $n$ (30), which gives an Item Mean of -0.48 (see Table 5).

Table 5. Example of Natural Logs of the Odds $\left(\log _{10} x / n-x\right)$

\begin{tabular}{|c|c|c|c|c|c|c|}
\hline $\begin{array}{c}\text { Dimension } \\
\mathbf{1}\end{array}$ & $\mathbf{5}$ & $\mathbf{4}$ & $\mathbf{3}$ & $\mathbf{2}$ & $\mathbf{1}$ & Total \\
\hline Item 1 & -0.52 & -0.12 & -0.70 & -0.96 & -1.15 & -3.43 \\
\hline Item 2 & -1.15 & 0.18 & -0.70 & -0.96 & -1.15 & -3.77 \\
\hline Item 3 & -0.95 & -0.18 & -0.30 & -0.96 & -1.15 & -3.53 \\
\hline Item 4 & -0.95 & -0.24 & -0.24 & -0.96 & -1.15 & -3.53 \\
\hline
\end{tabular}

Note: 5 - Very Satisfied, 4 - Satisfied, 3 - Moderately Satisfied, 2 - Of Little Satisfied, 1 - Not Satisfied

\section{Step 3: Estimate the Person Ability to Satisfy}

In estimating the Person Ability to Satisfy for person $i$, the raw scores were converted into odds of success, by calculating the ratio of the number of correct items on any scale $(y)$ to the number of incorrect items on that scale $(m-y)$. For example, if the total number of items $(m)$ is 4 , the raw data for each item answered by 30 persons are shown in Table 6 . The number of correct items answered by Person 1 on the Very Satisfied scale is 1 , while the number of incorrect items answered on the scale is 3 . So, the ratio is $1 / 3$ (see Table 7). If the number of correct items answered by any person on any scale is 0 , then the ratio $(y / m-y)$ is equal to 0 . If the number of incorrect items answered by any person on any scale is 0 , then the ratio $(y / m-y)$ is equal to the number of correct items. During the development of the BQAT prototype, the Person Ability to Satisfy was only estimated once with 49 items in order to produce an effective estimation.

Table 6. Example of Raw Data for 4 Items by 30 Persons

\begin{tabular}{|c|c|c|c|c|}
\hline Person & Item 1 & Item 2 & Item 3 & Item 4 \\
\hline Person1 & 5 & 4 & 3 & 3 \\
\hline Person2 & 5 & 4 & 4 & 4 \\
\hline Person3 & 4 & 3 & 4 & 4 \\
\hline Person4 & 3 & 4 & 4 & 4 \\
\hline Person5 & 5 & 4 & 4 & 4 \\
\hline Person6 & 5 & 5 & 5 & 5 \\
\hline Person7 & 4 & 4 & 4 & 4 \\
\hline
\end{tabular}


International Journal of Computer Applications Technology and Research

Volume 4- Issue 11, 846 - 859, 2015, ISSN:- 2319-8656

\begin{tabular}{|c|c|c|c|c|}
\hline Person & Item 1 & Item 2 & Item 3 & Item 4 \\
\hline Person8 & 4 & 3 & 3 & 3 \\
\hline Person9 & 5 & 4 & 3 & 3 \\
\hline Person 10 & 5 & 5 & 5 & 5 \\
\hline Person11 & 4 & 4 & 4 & 4 \\
\hline Person 12 & 2 & 2 & 2 & 2 \\
\hline Person 13 & 2 & 2 & 2 & 2 \\
\hline Person 14 & 4 & 4 & 4 & 4 \\
\hline Person 15 & 4 & 4 & 4 & 4 \\
\hline Person16 & 3 & 3 & 3 & 3 \\
\hline Person17 & 3 & 3 & 3 & 3 \\
\hline Person 18 & 5 & 4 & 4 & 4 \\
\hline Person19 & 4 & 4 & 4 & 4 \\
\hline Person20 & 3 & 4 & 4 & 3 \\
\hline Person21 & 4 & 4 & 4 & 4 \\
\hline Person22 & 4 & 4 & 3 & 3 \\
\hline Person23 & 3 & 3 & 3 & 3 \\
\hline Person24 & 4 & 4 & 3 & 3 \\
\hline Person25 & 2 & 2 & 2 & 2 \\
\hline Person26 & 4 & 4 & 3 & 3 \\
\hline Person27 & 1 & 1 & 1 & 1 \\
\hline Person28 & 4 & 4 & 3 & 3 \\
\hline Person29 & 4 & 4 & 5 & 5 \\
\hline Person30 & 1 & 1 & 1 & 1 \\
\hline
\end{tabular}

\begin{tabular}{|c|c|c|c|c|c|}
\hline Person & $\mathbf{1}$ & $\mathbf{2}$ & $\mathbf{3}$ & $\mathbf{4}$ & $\mathbf{5}$ \\
\hline Person13 & 0 & 4 & 0 & 0 & 0 \\
\hline Person14 & 0 & 0 & 0 & 4 & 0 \\
\hline Person15 & 0 & 0 & 0 & 4 & 0 \\
\hline Person16 & 0 & 0 & 4 & 0 & 0 \\
\hline Person17 & 0 & 0 & 4 & 0 & 0 \\
\hline Person18 & 0 & 0 & 0 & $3 / 1$ & $1 / 3$ \\
\hline Person19 & 0 & 0 & 0 & 4 & 0 \\
\hline Person20 & 0 & 0 & $2 / 2$ & $2 / 2$ & 0 \\
\hline Person21 & 0 & 0 & 0 & 4 & 0 \\
\hline Person22 & 0 & 0 & $2 / 2$ & $2 / 2$ & 0 \\
\hline Person23 & 0 & 0 & 4 & 0 & 0 \\
\hline Person24 & 0 & 0 & $2 / 2$ & $2 / 2$ & 0 \\
\hline Person25 & 0 & 4 & 0 & 0 & 0 \\
\hline Person26 & 0 & 0 & $2 / 2$ & $2 / 2$ & 0 \\
\hline Person27 & 4 & 0 & 0 & 0 & 0 \\
\hline Person28 & 0 & 0 & $2 / 2$ & $2 / 2$ & 0 \\
\hline Person29 & 0 & 0 & 0 & $2 / 2$ & $2 / 2$ \\
\hline Person30 & 4 & 0 & 0 & 0 & 0 \\
\hline Note: 5 & 0 ry & 0 & 0 & 0 & 0 \\
\hline
\end{tabular}

Note: 5 - Very Satisfied, 4 - Satisfied, 3 - Moderately Satisfied, 2 - Of Little Satisfied, 1 - Not Satisfied

\section{Step 4: Calculate the Person Mean}

The natural logs of these odds (excluding 0 ) were calculated and aggregated to obtain an estimate of the Person Ability to Satisfy for each person. The total of Person Ability to Satisfy was calculated by summing up the Person Ability to Satisfy for each person. Its value was then divided by the number of items to get the Person Mean. Based on the above example, the Person Mean is 1.93 logits. Similar to Step 3, the Person Mean was also calculated once.

Step 5: Compute the Probability of Dimension 1 to be Satisfied

The probability of Dimension 1 to be satisfied was computed by substituting $B_{n}, D_{i}$, and $F_{k}$ in formula 3.5 (see Chapter 3 ) with the Person Mean, Item Mean, and 0 respectively. We set the threshold, $F_{k}$, equal to 0 because it is calculated as a dichotomous 50/50 point [44].

$$
\begin{aligned}
P_{\text {nik }} & =\frac{e^{\left(B_{n}-D_{i}-F_{k}\right)}}{1+e^{\left(B_{n}-D_{i}-F_{k}\right)}} \\
& =\frac{e^{1.93+0.48-0}}{1+e^{1.93+0.48-0}} \\
& =0.9176
\end{aligned}
$$

The percentage of the probability of Dimension 1 for the above examples is $92 \%$. Given we have 11 families or 
dimensions in this study, Step 1, 2, and 5 were repeated for all 11 families.

\section{Step 6: Estimate the Probability of the Blog to be of Good} Quality

Finally, the probability of the blog to be of good quality was estimated by aggregating the products of the assigned weights and the probability for each family to be satisfied. For the dummy blog, in this case a Personal Diary blog, the assigned weights were derived from the same blog category. Table 6.8 shows the probability of the family to be satisfied $(P(\theta)$, the assigned weights $\left(w_{i}\right)$, and the product of the assigned weights and the probability of each family to be satisfied $\left(P(\theta)_{i} \times w_{i}\right)$, for the dummy blog.

Table 8. The Probability of the Family to be Satisfied $\left(P(\theta)_{i}\right)$, Weights $\left(w_{i}\right)$, and the Product of the Weights

Assigned and the Probability of Each Family to be Satisfied $\left(P(\theta)_{i} \times w_{i}\right)$ for the Dummy Blog

\begin{tabular}{|c|c|c|c|}
\hline Family & $\begin{array}{c}\text { Probability, } \\
\boldsymbol{P}(\boldsymbol{\theta})_{\boldsymbol{i}}\end{array}$ & $\begin{array}{c}\text { Weight, } \\
\boldsymbol{w}_{\boldsymbol{i}}\end{array}$ & $\begin{array}{c}\boldsymbol{P}(\boldsymbol{\theta})_{\boldsymbol{i}} \\
\mathbf{X} \boldsymbol{w}_{\boldsymbol{i}}\end{array}$ \\
\hline Accuracy & 70 & 0.0897 & 6.2790 \\
\hline Completeness & 80 & 0.0874 & 6.9920 \\
\hline Currency & 69 & 0.0915 & 6.3135 \\
\hline Engaging & 75 & 0.0851 & 6.3825 \\
\hline Reputation & 69 & 0.0786 & 5.4234 \\
\hline Info Representation & 69 & 0.0999 & 6.8931 \\
\hline Navigation & 69 & 0.0910 & 6.2790 \\
\hline
\end{tabular}

\begin{tabular}{|c|c|c|c|}
\hline Family & $\begin{array}{c}\text { Probability, } \\
\boldsymbol{P}(\boldsymbol{\theta})_{i}\end{array}$ & $\begin{array}{c}\text { Weight, } \\
\boldsymbol{w}_{\boldsymbol{i}}\end{array}$ & $\begin{array}{c}\boldsymbol{P}(\boldsymbol{\theta})_{\boldsymbol{i}} \\
\mathbf{x} \boldsymbol{w}_{\boldsymbol{i}}\end{array}$ \\
\hline Visual Design & 71 & 0.1013 & 7.1923 \\
\hline Readability & 69 & 0.0964 & 6.6516 \\
\hline Accessibility & 69 & 0.0940 & 6.4860 \\
\hline $\begin{array}{c}\text { Blog Technical } \\
\text { Features }\end{array}$ & 72 & 0.0851 & 6.1272 \\
\hline \multicolumn{3}{|c|}{$\sum \boldsymbol{P}(\boldsymbol{\theta})_{i} \times \boldsymbol{w}_{\boldsymbol{i}}$} & $\mathbf{7 1}$ \\
\hline
\end{tabular}

\section{FINDINGS AND RESULTS OF THE TECHNOLOGY ACCEPTANCE TEST}

The Technology Acceptance Test was conducted to gauge the acceptance of the Blog Quality Assessment Tool. This section is divided into two sub-sections; the fit statistics of the Technology Acceptance Test, and the results of the test.

\subsection{Fit Statistics of the Technology Acceptance Test}

The summary statistics for the analysis of the sample of 35 blog-readers on the 9 polytomous scale items comprising the Technology Acceptance Test items are shown in Figure 19. The summary fit statistics for Items and Persons show satisfactory fit to the model. The mean square fit (IMNSQ and OMNSQ) statistics and the $z$ statistics (Infit and Outfit ZSTD) for Items and Persons are close to their expected values, +1 and 0 , respectively.

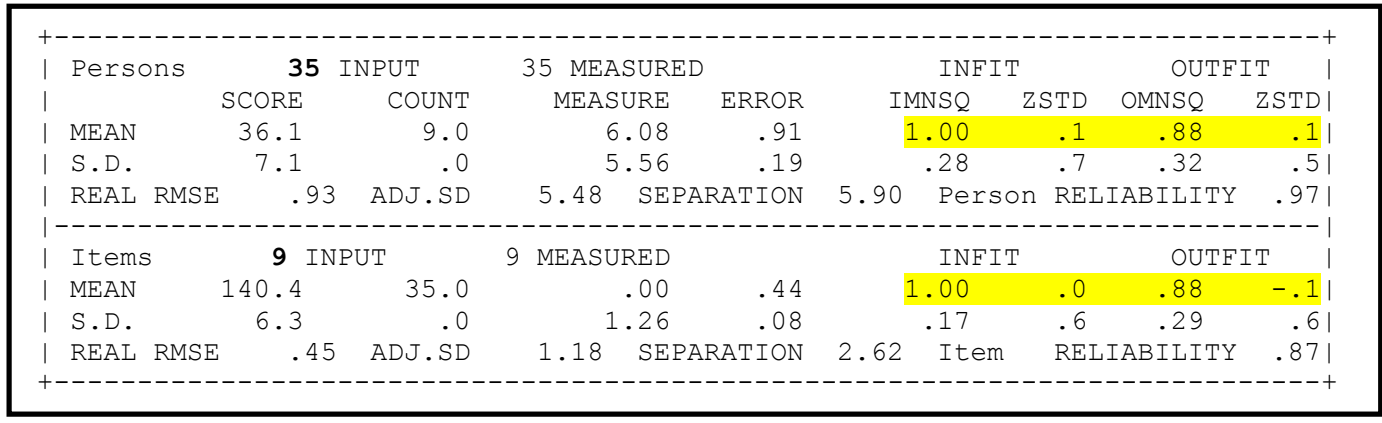

Figure 19. Summary Statistics of Technology Acceptance Test

The Wright map in Figure 20 demonstrates the distribution of blog-readers on the left, represented by r01-r30, and the distribution of item agreement on the right, represented by item ID (refer Table 9). The most easily endorsed item is PEU2 (I find that the Blog Quality Assessment Tool is easy to use) located at -2.93 logits (SE .62), while the item that is most difficult to endorse is $\mathrm{A} 2$ (My attitude toward using the Blog Quality Assessment Tool is very favourable) located at the top of the Item distribution at +1.73 logits (SE .38). The
Person distribution confirms the result from the summary statistics. The easiest to endorse blog-readers are r05, r17, r28, r29, and r30 located at +12.53 logits (SE 1.10), while the most difficult to endorse blog-reader is $\mathrm{r} 03$ located at the bottom of the Person distribution at -6.63 logits (SE .68). The mean of the Person distribution is higher than the mean of the Item distribution. This indicates that majority of the blog-readers involved in the Technology Acceptance Test have the tendency to agree with most of the items. 


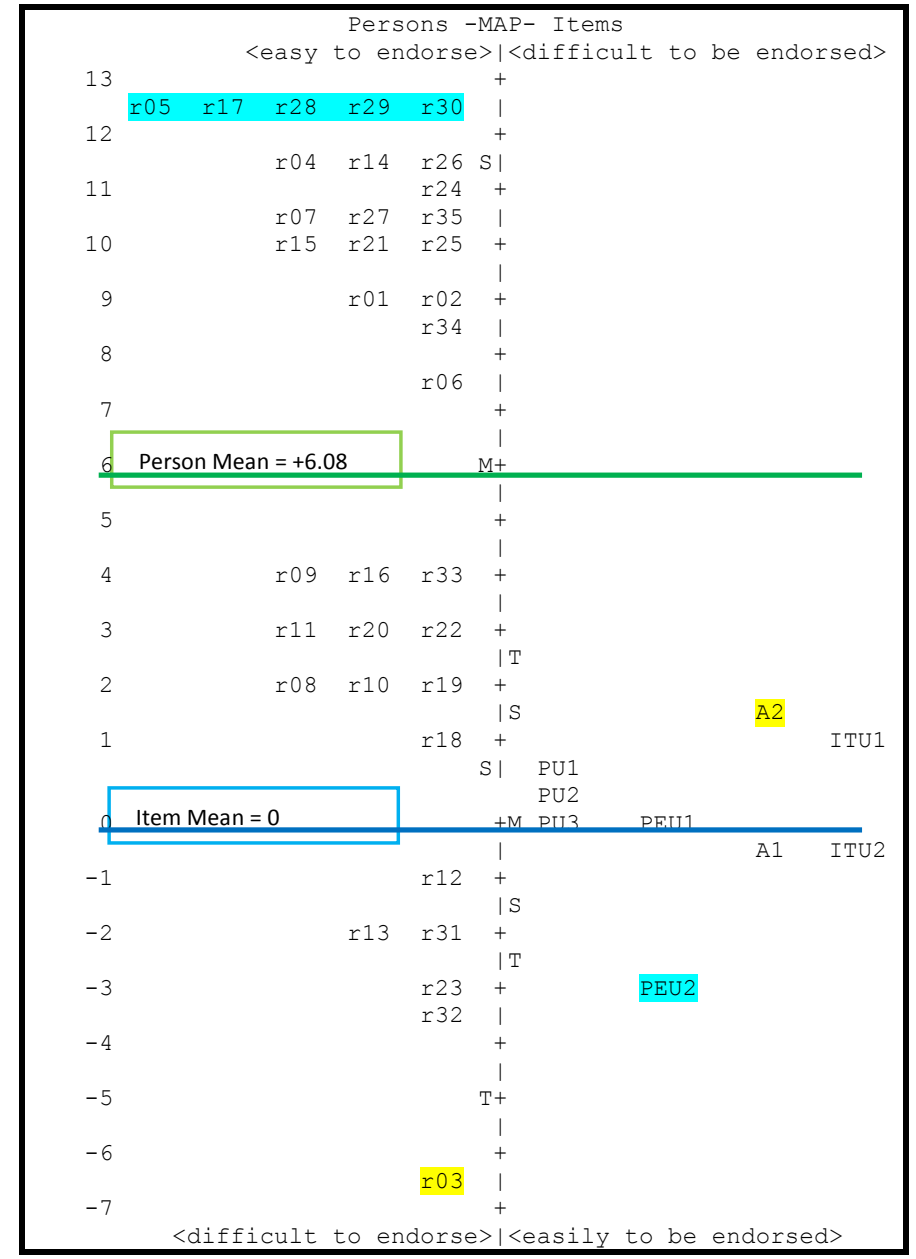

Figure 20. Wright Map of the Technology Acceptance Test

Figure 21 shows the Item statistics in Measure order. The Rasch fit statistics disclose that item A1 behaved more erratically than expected with an Infit MNSQ value > 1.4. However, after confirming that the Infit Z-Std is within the range, it is accepted in this analysis. Other items fit sufficiently to the model, with their Infit and Outfit Meansquare values and Infit and Outfit Z-std values all lying within the acceptable range.

\begin{tabular}{|c|c|c|c|c|c|}
\hline \multicolumn{6}{|c|}{ 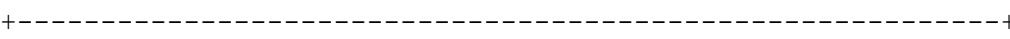 } \\
\hline | NUMBER & SCORE & MEASURE & S.E. | MNSQ & ZSTD|MNSQ & zSTD| Item \\
\hline--- & & ----- & -----+---- & ----+---- & -----+----- \\
\hline 7 & 130 & 1.73 & $.38 \mid 1.04$ & .31 .93 & $-.1 \mid \mathrm{A} 2$ \\
\hline 8 & 134 & 1.15 & .381 .90 & -.51 .82 & $-.6 \mid$ ITU1 \\
\hline 1 & 138 & .55 & $.39 \mid 1.02$ & $.2 \mid 1.08$ & $.4 \mid$ PU1 \\
\hline 2 & 139 & .39 & .401 .84 & -.81 .70 & $-1.0 \mid$ PU2 \\
\hline 3 & 140 & .23 & .401 .98 & $.0 \mid 1.15$ & .61 PU3 \\
\hline 4 & 140 & .23 & $.40 \mid 1.03$ & $.2 \mid 1.04$ & .2| PEU1 \\
\hline 6 & 145 & -.67 & $.45 \mid 1.43$ & $1.5 \mid 1.29$ & $.7 \mid \mathrm{A} 1$ \\
\hline 9 & 145 & -.67 & .451 .89 & -.31 .58 & $-.9 \mid$ ITU2 \\
\hline 5 & 153 & -2.93 & .621 .86 & $-.2 \mid .31$ & $-.3 \mid$ PEU2 \\
\hline
\end{tabular}

Figure 21. Item Measure of the Technology Acceptance Test

Note: Acceptable range for Infit and Outfit Mean-square is between 0.6 to 1.4 [45] and acceptable range for Infit and Outfit Z-std is between -2 to $+2[44]$ 
The Rasch fit statistics are further inspected by examining the Person statistics. Figure 22 displays the Person statistics in Measure order. There are two possible under-fitting persons; r34, and r06 having Infit MNSQ values > 1.4. Yet, they are kept in the analysis as their Infit Z-std, Outfit MNSQ, and Outfit Z-Std values are within bounds.

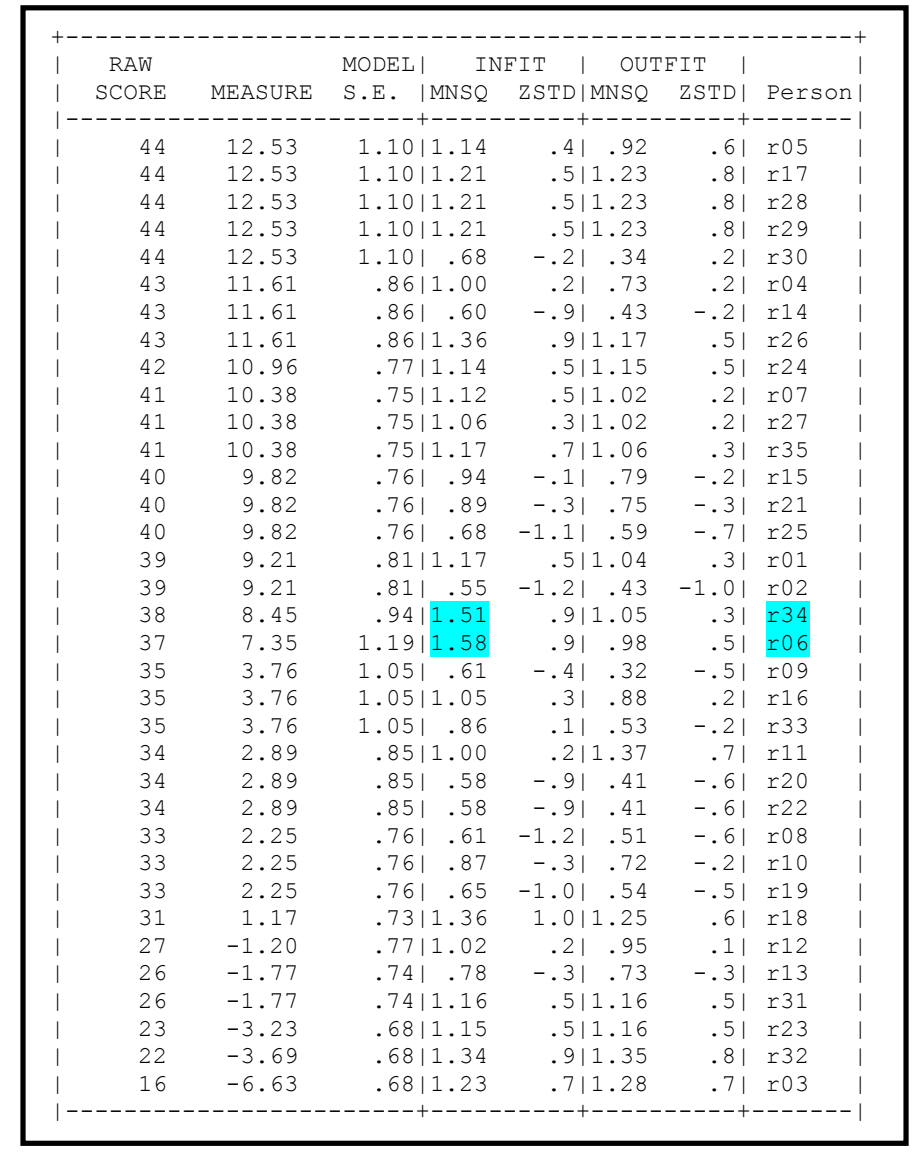

Figure 22. Person Measure of the Technology Acceptance Test

Note: Acceptable range for Infit and Outfit Mean-square is between 0.6 to 1.4 [45] and acceptable range for Infit and Outfit Z-std is between -2 to $+2[44]$

The principal contrast analysis of the Rasch residual variance is shown in Figure 23. The variance explained by measures is significantly good $(91.1 \%)$. The uni-dimensionality of the technology acceptance test instrument is strongly confirmed by having a good unexplained variance in the first contrast $(2.0 \%)$.

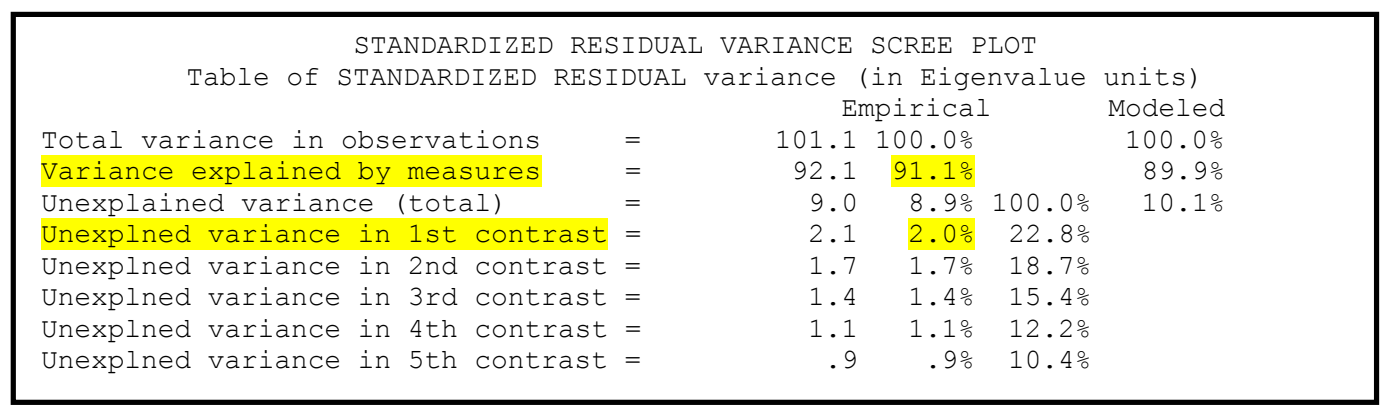

Figure 23. Principal Contrast Analysis of the Technology Acceptance Test

Note: Variance explained by measures should be $\geq 50 \%$ and unexplained variance in the first contrast should be $\leq 15 \%$ [46]

Figure 24 depicts the category probability curves for all items. This corroborates that the 4 thresholds are in order and the probability curves for all categories are not flat. It shows that our 5-point rating scale developed for this questionnaire yields the highest quality measures for the construct of interest. 
International Journal of Computer Applications Technology and Research

Volume 4- Issue 11, 846 - 859, 2015, ISSN:- 2319-8656

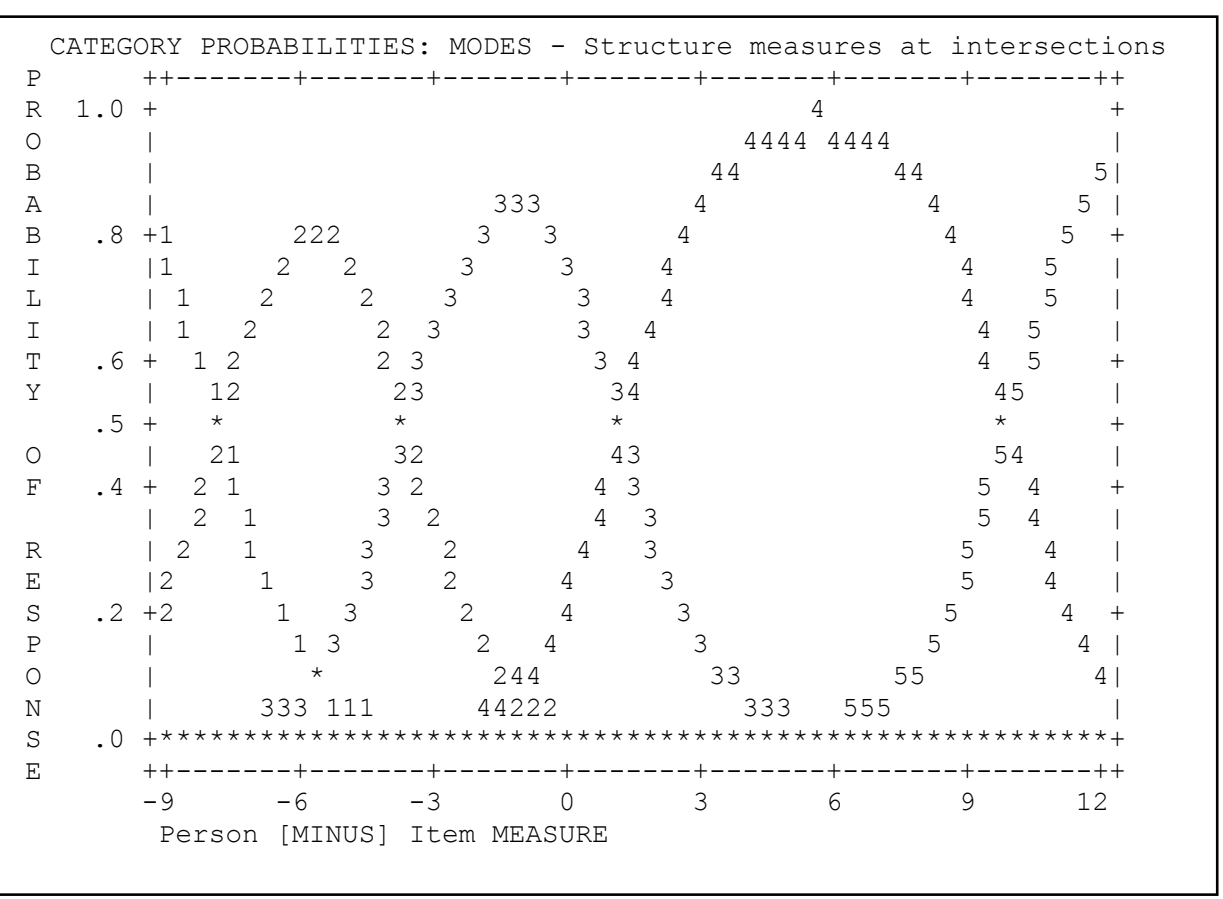

Figure 24. Category Probabilities of the Technology Acceptance Test

\subsection{Results of the Technology Acceptance}

\section{Test}

After all the data were confirmed to fit to the Rasch model, the probability of each item to be endorsed by blog-readers, on average, was calculated and the results are presented in Table 9. The results show that blog-readers perceived ease of use and usefulness as significant features of the BQAT system. This implies that the BQAT system is easy, effective, and useful to help blog-readers make a good quality assessment. Blog-readers also displayed a significantly positive attitude towards using the tool and intend to use it. Most importantly, blog-readers significantly agree that bloggers should participate in the blog quality assessment project.

Table 9. The Probability of Factors and Items to be Endorsed

\begin{tabular}{|c|c|c|c|}
\hline Factor & $\mathbf{P}(\boldsymbol{\theta})(\%)$ & Item ID and Description & $\mathrm{P}(\boldsymbol{\theta})(\%)$ \\
\hline \multirow{2}{*}{$\begin{array}{l}\text { PEU } \\
\text { Perceived } \\
\text { Ease of Use }\end{array}$} & \multirow[t]{2}{*}{99.85} & $\begin{array}{l}\text { PEU1 } \\
\text { Learning to use the Blog Quality Assessment Tool is easy for me. }\end{array}$ & 99.71 \\
\hline & & $\begin{array}{l}\text { PEU2 } \\
\text { I find that the Blog Quality Assessment Tool is easy to use. }\end{array}$ & 99.99 \\
\hline \multirow[t]{3}{*}{$\begin{array}{l}\text { PU } \\
\text { Perceived } \\
\text { Usefulness }\end{array}$} & \multirow[t]{3}{*}{99.66} & $\begin{array}{l}\text { PU1 } \\
\text { The Blog Quality Assessment Tool enables me to complete } \\
\text { assessing the blog quality quickly. }\end{array}$ & 99.60 \\
\hline & & $\begin{array}{l}\text { PU2 } \\
\text { Using the Blog Quality Assessment Tool will help me improve my } \\
\text { ability to make a good blog quality assessment. }\end{array}$ & 99.66 \\
\hline & & $\begin{array}{l}\text { PU3 } \\
\text { The Blog Quality Assessment Tool makes the blog quality } \\
\text { assessment task more effective. }\end{array}$ & 99.71 \\
\hline \multirow{2}{*}{$\begin{array}{l}\text { A } \\
\text { Attitude } \\
\text { toward } \\
\text { Using }\end{array}$} & \multirow[t]{2}{*}{99.31} & $\begin{array}{l}\text { A1 } \\
\text { Using the Blog Quality Assessment Tool for assessing the quality of } \\
\text { my favourite blog is a good idea. }\end{array}$ & 99.88 \\
\hline & & $\begin{array}{l}\mathrm{A} 2 \\
\text { My attitude toward using the Blog Quality Assessment Tool is very } \\
\text { favourable. }\end{array}$ & 98.73 \\
\hline \multirow[t]{2}{*}{$\begin{array}{l}\text { ITU } \\
\text { Intention to } \\
\text { Use }\end{array}$} & \multirow[t]{2}{*}{99.58} & $\begin{array}{l}\text { ITU1 } \\
\text { I intend to use the Blog Quality Assessment Tool when it becomes } \\
\text { available on my favourite blog. }\end{array}$ & 99.28 \\
\hline & & $\begin{array}{l}\text { ITU2 } \\
\text { I think that bloggers should participate in this blog quality } \\
\text { assessment project. }\end{array}$ & 99.88 \\
\hline
\end{tabular}




\section{CONCLUSION AND FUTURE WORKS}

A prototype of Blog Quality Assessment Tool (BQAT) was successfully developed. The main functions of the BQAT are to calculate the probability of a blog to be of good quality, and to accumulate the results for the assessed blog. Thus, blogreaders can easily obtain information on the quality of the blogs visited. This assessment tool can also be used to manage and control a blog's expansion, such that only high quality blogs continue to exist in the blogosphere. The Technology Acceptance Test was conducted to investigate whether or not our prototype of the Blog Quality Assessment Tool was accepted by blog-readers. This study explored the impact of perceived usefulness, perceived ease of use, attitude, and intention to use the system on blog-users' acceptability. Results indicate that blog-readers significantly agree that the Blog Quality Assessment Tool is easy, effective, and useful to them in assessing blog quality. This study also shows that the more satisfied the blog is, the higher its quality.

In future, we will invite bloggers and blog readers to participate assessing actual blogs in different blog categories, by using the Blog Quality Assessment Tool.

\section{REFERENCES}

[1] Lenssen, P. (2006). Good blog writing style. Retrieved January 2, 2009 from http://blogoscoped.com/archive/2006-10-11-n47.html.

[2] Merlin, M. (2008). What makes for a good blog. Retrieved January 2, 2009 from http://www.43folders.com/2008/08/19/good-blogs.

[3] Rowse, D., \& Garrett, C. (2008). ProBlogger: Secrets for Blogging Your Way to a Six-Figure Income. Indianapolis, Indiana: Wiley Publishing Inc.

[4] Strauss, L. (2005). Blog design checklist. Retrieved January 3, 2009 from http://www.successfulblog.com/1/blog-design-checklist/

[5] Zain, Z. M., Ghani, A. A. A., Abdullah, R., Atan, R., \& Yaakob, R. (2011). Application of Rasch Model in validating the content of measurement instrument for blog quality. In J. M. Zain, W. M. W. Mohd, \& E. ElQawasmeh (Eds.). Software Engineering and Computer Systems (Vol. 180): Springer Publishing Co., Heidelberg/Berlin, 125-136.

[6] Zain, Z. M., Ghani, A. A. A., Abdullah, R., Atan, R., \& Yaakob, R. (2012). Blog quality measurement: analysis of criteria using the Rasch Model. Int. J. New Comput. Archit. Their Appl, 1(1), 665-682.

[7] Zain, Z. M., Ghani, A. A. A., Abdullah, R., Atan, R., \& Yaakob, R. (2013). Blog quality model. Int. J. Webbased Communities, 9(1), 25-50.

[8] Zhang, P., von Dran, G., Blake, P., \& Pipithsuksunt, V. (2001). Important Design Features in Different Web Site Domains. e-Service Journal, 1(1), 77-91.

[9] Katerattanakul, P., \& Siau, K. (2001). Information quality in internet commerce design. In M. Piattini, C. Calero, \& M. Genero (Eds.), Information and Database Quality: Kluwer Academic Publishers, Norwell, MA, 4546.
[10] Naumann, F., \& Rolker, C. (2000). Assessment methods for information quality criteria. In Proceedings of the 5th International Conference on Information Quality (IQ2000). MIT, Cambridge, MA, (pp. 148-162).

[11] Graefe, G. (2003). Incredible Information on the Internet: Biased information provision and a lack of credibility as a cause of insufficient information quality. In Proceedings of the 8th International Conference on Information Quality (IQ2003). MIT, Cambridge, MA, (pp. 133-146).

[12] Melkas, H. (2004). Analyzing information quality in virtual service networks with qualitative interview data. In Proceedings of the 9th International Conference on Information Quality (IQ2004). MIT, Cambridge, MA, (pp. 74-88).

[13] Eppler, M. (2001). A generic framework for information quality in knowledge-intensive processes. In Proceedings of the 6th International Conference on Information Quality (IQ2001). Cambridge, MA, (pp. 329-346).

[14] Katerattanakul, P., \& Siau, K. (1999). Measuring Information Quality of Web Sites: Development of an Instrument. In Proceedings of the 20th International Conference on Information System (1999). Association for Information Systems, Atlanta, GA, (pp. 279-285).

[15] Caro, A., Calero, C., Caballero, I., \& Piattini, M. (2008). A proposal for a set of attributes relevant for Web portal data quality. Software Quality J, 16(4), 513-542.

[16] Banks, M. A. (2008). Blogging Heroes: Interviews with 30 of the World's Top Bloggers. Indianapolis, Indiana: Wiley Publishing Inc.

[17] Tan, J.-E., \& Ibrahim, Z. (2008). Blogging and Democratization in Malaysia. A New Civil Society in the Making. Petaling Jaya: SIRD.

[18] Hopkins, J. (2009). The "ideal type" blog. Retrieved June 12, 2009 from http://jualianhopkins.net/index.php?/archives/240-Theideal-type-blog.html

[19] Zarizi, S. S. (2006). 70 weblog paling popular di Malaysia. Retrieved January 2, 2009 from http://syedsyahrul.blogspot.com/2006/05/70-weblogpaling-popular-di-malaysia_28.html

[20] Zain, Z. M., \& Abdul Ghani, A. A. (2014). Importance Analysis of a Blog Quality Model for Criteria and Families in Different Blog Categories. International Journal of Virtual Communities and Social Networking, 6(3), 17-56.

[21] McCall, J. A., Richards, P. K., \& Walters, G. F. (1977). Factors in Software Quality. New York: General Electric Company.

[22] Boehm, B. (1978). Characteristics of Software Quality. New York: North Holland Publishing Co.

[23] Dromey, R. G. (1995). A Model for Software Product Quality. IEEE Transactions on Software Engineering, 21(2), 146-162.

[24] ISO 9126. (1991). Software product evaluation - Quality characteristics and guidelines for their use. International Organization for Standardization. Retrieved May 18, 2009 from http:www.iso.org 
[25] Olsina, L., \& Rossi, G. (2002). Measuring Web Application Quality with WebQEM. IEEE Multimedia, 9(4), 20-29.

[26] Calero, C., Ruiz, J., \& Piattini, M. (2005). Classifying Web Metrics using The Web Quality Model. Online Information Review, 29(3), 227-248.

[27] Malak, G., Badri, L., Badri, M., \& Sahraoui, H. (2004). A Quality Model for Web-based Applications. In Proceedings of the 5th International Conference on Electronic Commerce and Web Technologies (ECWeb2004). Springer, Zaragosa, Spain, (pp. 316-327).

[28] Olsina, L. (1999). Web-site quality evaluation method: a case study on museums. In Proceedings of the 2nd International Conference on Software Engineering Workshop on Web Engineering (ICSE1999). Los Angeles, CA.

[29] Olsina, L., Godoy, D., Lafuente, G., \& Rossi, G. (1999). Assessing the quality of academic websites. New Rev. Hypermedia Multimed. J. 5(1), 81-103.

[30] Olsina, L., Lafuente, G., \& Rossi, G. (2000). Ecommerce site evaluation: a case study. In K. Bauknecht, S. Madria, \& G. Pernul (Eds.), Electronic Commerce and Web Technologies (Vol. 1875): Springer Publishers, Heidelberg/Berlin, 239-252.

[31] Lee, Y. W., Strong, D. M., Kahn, B. K., \& Wang, R. Y. (2002). AIMQ: a methodology for information quality assessment. Information \& Management, 40(2), 133-146.

[32] Strong, D., Lee, Y., \& Wang, R. (1997). Data Quality in Context. Communications of the ACM, 40(5), 103-110.

[33] Winkler, W. E. (2004). Methods for evaluating and creating data quality. Information Systems Data Quality in Cooperative Information Systems, 29(7), 531-550.

[34] Bouzeghoub, M., \& Kedad, Z. (2001). Quality in Data Warehousing. In M. Piattini, C. Calero, \& M. Genero (Eds.), Information and Database Quality: Kluwer Academic Publishers.

[35] Zhu, Y., \& Buchmann, A. (2002). Evaluating and Selecting Web Sources as external Information Resources of a Data Warehouse. In Proceedings of the 3rd International Conference on Web Information Systems Engineering (2002). Singapore (pp. 149-160).

[36] Aboelmeged, M. (2000). A Soft System Perspective on Information Quality in Electronic Commerce. In Proceedings of 5th Conference on Information Quality (IQ2000). MIT, Cambridge, MA, (pp. 318-319).

[37] Gertz, M., Özsu, M. T., Saake, G., \& Sattler, K.-U. (2004). Report on the Dagstuhl Seminar "Data Quality on the Web". SIGMOD Rec., 33(1), 127-132.

[38] Sommerville, I. (2010). Software Engineering (9 ed.). Essex: Pearson Education Limited.

[39] Mich, L., Franch, M., \& Gaio, L. (2003). Evaluating and Designing Web Site Quality. IEEE Computer Magazine, 10(1), 34-43.

[40] Olsina, L., Godoy, D., Lafuente, G. J., \& Rossi, G. (2001). Specifying Quality Characteristics and Attributes for Websites. In S. Murugesan \& Y. Deshpande (Eds.), Web Engineering, 2016 (pp. 266-278): Springer Berlin/Heidelberg.

[41] Signore, O. (2005). A Comprehensive Model for Web Sites Quality. Paper presented at the Seventh IEEE International Symposium on Web Site Evolution (WSE'05), Budapest, Hungary.

[42] Evans, J. R., \& King, V. E. (1999). Business-to-business Marketing and the World Wide Web: Planning, Managing and Assesing Web Sites. Industrial Marketing Management, 28(4), 343-358.

[43] Andrich. D. (1978). A rating formulation for ordered response categories. Psychometrika, 43(4), 561-573.

[44] Bond, T. V., \& Fox, C. M. (2007). Applying The Rasch Model: Fundamental Measurement in the Human Sciences (2nd ed.). New Jersey: Lawrence Erlbaum Associates.

[45] Wright, B. D., Linacre, M., Gustafsson, J.-E., \& MartinLoff, P. (1994). Reasonable Mean-square Fit Values. Rasch Measurement Transactions, 8(3), 370.

[46] Fisher, W. P., Jr. (2007). Rating Scale Instrument Quality Criteria. Rasch Measurement Transactions, 21(1), 1095. 